\title{
GRAVITATIONAL RADIATION BY ULTRARELATIVISTIC BODIES
}

\author{
PETER JOCELYN WESTERVELT \\ University of Texas, Austin, Tex. 78712, U.S.A. \\ and \\ Brown University, Providence, R.I. 02912, U.S.A.
}

\begin{abstract}
I have shown (Westervelt, 1966) that ultrarelativistic bodies do not radiate gravitational waves in the forward direction. This work has been extended so as to apply to circular orbits. Even if low efficiency of generation precludes direct observation of gravitational waves, indirect evidence for their existence is available in a recent analysis (Westervelt, 1969) of Shapiro's fourth test of general relativity.
\end{abstract}

\section{References}

Westervelt, P. J.: 1966, J.E.T.P. Letters 4, 225.

Westervelt, P. J.: 1969, Acta Phys. Polon. 35, 203. 